this having caused death, as, even before putrefaction begins, air is often found in the veins. Had the air been analyzed, our information would have been better.

M. Demarquay thought the death was one from chloroform. Blood was always frothy in cases dead from entrance of air into the veins. He thinks the method of giving chloroform should be changed, and it should be given in small, and always known, quantities.

M. Le Fort spoke of the misleading results of experiments on animals. The manner of death in this case was different from the mode of death by chloroform. According to his personal researches, there are four ways in which a patient may die under chloroform :-1. By suicide, asphyxiated, when the patient is found with a compress over the nose ; 2. By stopping of the heart-action during the period of excitement; 3 . By occlusion of the orifice of the larynx when thoroughly under, by the tongue falling back on the glottis, paralyzed; 4. By syncope, specially in cases when the patient is chloroformed in the sitting posture. To restore similar cases, insufflation from mouth to mouth is not to be trusted. The method of Sylvester is better than that of Marshall Hall.

$M$. Despeses then dwelt on the existence of air in the veins.

$M$. Perrin objected to M. Le Fort's decision, and thought that chloroform acted as a poison.

$M$. Giraldes believed that both chloroform and air in the veins conspired to cause the death of the patient.-Gazette des Hôpitaux, No. 29, 1872.

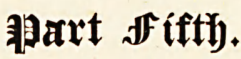

\section{MEDICAL NEWS.}

The Health of the City.-The mortality in the city from smallpox continues steadily on the decline. During the past week the registered deaths through this epidemic numbered 5, all of them occurring in the Old Town. The number of patients admitted into the New Royal Infirmary was $11-3$ died, and 12 were discharged cured. Since the opening of the hospital on 5th December last, the total admissions have been 1335, while 261 have died and 1028 have been discharged cured, so that there are now 46 under treatment-24 males and 22 females. In the Old Royal Infirmary there are 2 smallpox, 6 fever, and 3 scarlet fever patients under treatment, and 15 in the Canongate Fever Hospital. -Scotsman, 17th June.

Important Decision.- Mr M'Namara has recently ruled in the case Stevenson $v$. Gliddon, that the possession of a medical degree from the University of Edinburgh does not entitle its 
possessor to recover for medicine supplied to his patient, except in connexion with visits or advice. This decision is so entirely contrary to what has hitherto been believed to be the correct interpretation of the Medical Act, that it has taken the profession by surprise.

The Senatus Academicus of the Edinburgh University have, however, ruled that "The graduates of Scotch Universities have no right to recover for medicines supplied by them, that is not enjoyed by members of other British Universities or medical corporations, including the College of Surgeons of England, to which Dr Stevenson also belongs. The Faculties do not think that the University of Edinburgh is called upon to interfere in this case."

Volunteer Surgeons.-Mr Cardwell, knowing the difficulties in the way of gaining a professional livelihood, and sympathizing with the sufferers, has fallen upon an important method of supplementing the incomes of the Volunteer surgeons, and has had the great liberality of offering for their compulsory acceptance the large sum of $2 d$. per head per week for the entire permanent staff of each regiment with their families, who are to receive all necessary attendance-even midwifery - and medicine for that sum. As most of the Volunteer surgeons are men of some position and without spare time, who joined the force from patriotic motives-to give and not to gain eclat-they will no doubt gratefully appreciate $\mathrm{Mr}$ Cardwell's kindness, which can indeed be regarded in no other light than as a gentle hint that the Volunteer force is doomed, and that they had better all resign, beginning with the surgeons.

Sir William Gull and Mr H. G. Sutton have recently (28th May) read to the London Medical and Chirurgical Society an important paper, in which they refer to the contracting kidney as part and parcel of a general morbid change, the essence of which is a hyalin-fibroid alteration of the capillaries, and of the tunica adventitia of the arterioles. Dr George Johnson, it will be remembered, refers the thickening of the walls of the arterioles in such cases to muscular hypertrophy produced by a permanent stopcock action induced by a desire to prevent impure blood getting to the tissues, and itself reacting on the heart, which hypertrophies in virtue of the vigorous efforts it insanely makes to overcome the wisdom (one-sided) of the arterioles. According to Gull and Sutton, there are no such diversities of opinion prevading our tissues, but each apparent complication is evolved in a natural manner from the preceding conditions, the whole being ultimately referred to a premature senility commencing in the vascular system, and revealing itself by the so-called arterio-capillary fibrosis, which may commence in the kidneys or in other organs, which latter may even be far advanced in the morbid change without the kidrieys being much affected. This theory has a clear and simple look about it, and it may be a true discovery; meanwhile there are many difficulties in the way of its acceptance, the most important of these being the 
fact that such arterio-capillary and cardiac changes have been hitherto entirely unnoticed in the analogous disease (cirrhosis) of the liver, while if Gull and Sutton's theory be true, the vascular changes ought to be at least as well marked in it as in those cases in which the affection of the kidney is most prominent.

Professor Rainy has resigned the chair of Medical Jurisprudence in the University of Glasgow. The appointment of a successor rests with the Crown; and the candidates already in the field are, Dr Arthur Gamgee, F.R.S.E., Lecturer on Physiology, Edinburgh, and Examiner in Medical Jurisprudence to the University of London, etc., etc. ; Dr P. A. Simpson, M.A., Lecturer on Medical Jurisprudence in Anderson's University, Glasgow; and Dr St Clair Gray, at present Assistant to Professor Rainy and Dr Adams.

\section{CORRESPONDENCE.}

To the Editor of the Edinburgh Medical Journal.

St Andrews, 20th June 1872.

Sir,-At the last meeting of the Obstetrical Society of Edinburgh, there was a very interesting specimen of an aborted human ovule, between the second and third month of gestation, which was given to $\mathrm{Dr}$ Keiller, who refuses to have it examined anatomically. As I think it would afford a crucial proof of the automatic circulation of the embryo, as independent of the mother as the chick in ovuloovi, I very strongly pressed $\mathrm{Dr}$ Keiller to allow it to be examined, and, if recent enough, to have it also injected.

Thus completely failing, I appeal to the professional readers of your Journal, if a similar abortion occurs to any of them, they will send it to Mr Stirling, the successful anatomical injector of delicate embryonic developments at the University of Edinburgh. He has cordially assented, and, if it should arrive in a fit condition, will inject it.

I consider that by the full examination of a similar ovule at the same stage of development, it will be proved that the automatic circulation of the embryo is carried on as independent of the maternal circulation as in the case of the chick in ovulo-ovi. It will explain how twins are each fully developed in this primary envelope, and in those rare cases of twins where only one is fully developed and the other arrested, but still each contained in its separate primary envelope. The case of extra-uterine gestation can also be explained. The Hunterian decidua reflexa is merely this primary ovular envelope.

I will be much obliged by your inserting this in the next number, before the break-up of the session.-Yours obliged,

$$
\text { W. Macdonald, M.D. }
$$

Erratum.-For the word "hair," in the last line of page 1124 of this Journal for June, read "cuticle." 